\title{
KONTRIBUSI GAGASAN JÜRGEN HABERMAS BAGI HERMENEUTIKA POSTMODERN
}

\author{
Erni M.C. Efruan
}

\section{PENDAHULUAN}

Hermeneutika dalam segala tahap perkembangannya sangat berpengaruh, bukan hanya dalam bidang teologi, tetapi juga dalam berbagai bidang pengetahuan manusia. Dalam Postmodern ini, orang yang mengaku ilmuwan atau filsuf, tidak bisa begitu saja mengabaikan hermeneutika.

Ironisnya, manusia Postmodern menyerang kekristenan karena beranggapan bahwa merekalah satu-satunya yang memiliki kebenaran. Berdasarkan pemikiran yang objektif dan metanaratif sekuler, manusia Postmodern tidak percaya adanya metanaratif-absolut. ${ }^{1}$ Sedangkan, kepercayaan berelasi erat dengan pemahaman, sementara semua interpretasi mencakup pemahaman. ${ }^{2}$ Untuk dapat menginterpretasi hal-hal metanaratif, maka pastinya terlebih dahulu harus memahami. Tentunya, memahami dan menginterpretasi adalah satu momen dalam satu proses yang menciptakan lingkaran hermeneutika; hermeneutika tidak dapat mempersempit ketergantungannya pada hal-hal lain. Di sini hermeneut mengahadapi dilema antara tetap objektif dan bersifat subjektif, atau antara tetap subjektif dan harus menjadi objektif.

Dengan demikian, adakah kontribusi dimensi gagasan atau pemikiran filsuf hermeneutika atau hermeneut bagi hermeneutis-teologis yang memadai di era Post Modern ini?

\footnotetext{
${ }^{1}$ Bnd. Henry Efferin, "Pascamodernisme dan Keyakinan Injili” dalam Jurnal Pelita Zaman, Jakarta: Mei-Oktober (1999), 1; bnd. Gene E. Veith, Jr., Postmodern Times (Wheaton: Crossway Book, 1994), 18-20.

${ }^{2}$ Menurut Habermas, pemahaman adalah suatu kegiatan dimana pengalaman dan pengetahuan teoritis berpadu menjadi satu. Pemahaman yang dimaksud adalah pemahaman monologis atau makna, yaitu pemahaman yang tidak melibatkan hubungan-hubungan faktual tetapi mencakup bahasa-bahasa 'murni' (mis. bahasa simbol). Bahasa dan pengalaman harus masuk ke dalam dialektik dengan tindakan. Oleh karenanya, bila kita hendak membuat interpretasi yang benar dan tepat, maka kita harus mengupayakan dialog antara bahasa dan pengalaman di satu sisi dan tindakan di sisi lain; Bnd. Jürgen Habermas, Knowledge and Human Interest (Boston: Beacon Press, 1972), 144.
} 


\section{POSTMODERN DAN HERMENEUTIKA}

Mencari dan menemukan kontribusi gagasan-gagasan atau pemikiran-pemikiran filsuf hermeneutika terkemuka saat kini Jürgen Hubermas telah menstimulir penulis untuk terlebih dahulu mengkaji hakekat postmodern dan hermeneutika pada bagian berikut ini.

\section{Postmodern}

Postmodern adalah suatu tantangan utama bagi kekristenan abad ke21 ini. Para pemikir Barat beranggapan bahwa manusia sudah melewati zaman Modern yang berlangsung mulai dari Abad Pencerahan (Aufklarung) sampai tahun 1960-an. ${ }^{3}$ Faktanya, terjadi perubahan budaya yang berlawanan dengan ciri khas zaman modern, yakni: inovasi yang lahir sebagai reaksi terhadap kemandulan dan kelumpuhan Abad Pertengahan. ${ }^{4}$ Pemikir lain seperti sejarawan Arnold Toynbee berpendapat bahwa Perang Dunia I merupakan saat berakhirnya Modernisme dan dimulainya Postmodern. ${ }^{5}$ Dengan demikian dapat dianggap bahwa pencetus istilah

${ }^{3}$ Bnd. Stanley J. Grenz, A Primer on Postmodern (Grand Rapids: Eerdmans, 1996), 7-20.

${ }^{4}$ Beberapa pemikir dengan berani mencoba untuk menggambarkan suasana baru ala Postmodern. Namun usaha mereka cenderung merefleksikan posisi yang menaruh simpati. Misalnya Sallie McFague memuat asumsi-asumsi Postmodern dalam tulisannya yang menginginkan adanya "penghargaan lebih besar terhadap alam, pengakuan akan pentingnya 'bahasa' dalam hidup manusia, pengurangan kekaguman terhadap teknologi, penerimaan tantangan dari agama-agama lain terhadap tradisi Yudeo-Kristen, kepekaan akan adanya wahyu baru, kepekaan akan adanya pergeseran dari posisi pria Barat berkulit putih dan kebangkitan mereka yang tertindas akibat gender, ras atau kelas sosial dan mungkin yang paling penting adalah bertumbuhnya kesadaran akan adanya salingketergantungan secara radikal dari semua pihak dan di dalam segala cara yang dapat dipikirkan," Lih. Sallie McFague, Metaphorical Theology (Philadelphia: Fotress Press, 1982), x-xi; bnd. Diogenes Allen, Christian Belief in a Postmodern Worl: The Full Wealth of Conviction (Lousville: Westminster/John Konox Press, 1989), 2; Istilah Postmodern dapat ditelusuri kembali dari tahun 1930-an, ketika sebuah perubahan besar terjadi dalam sejarah; Lih. Margaret Rose, "Defining the Post-Modern" in The Post Modern Reader, Charles Jenck, ed. (New York: St. Martin's Press, 1992), 119-136; Istilah Postmodern juga menunjuk kepada perkembangan dan pergeseran yang terjadi dalam dunia seni; bnd. Craig Van Gelder, "Postmodernism as an Energing Worldview," Calvin Theological Journal 26 (1991), 42.

5 The first instance of the word postmodernism cited by the Oxford English Dictionary is Dated 1949 from a book on architecture; bnd. Charles Jencks, What is PostModern? (New York: St. Martin's Press, 1989), 8. 
Postmodern adalah Arnold Toynbee dengan bukunya yang termahsyur berjudul Study of History. ${ }^{6}$ Ada pula yang mengatakan bahwa karya Friedrich Nietzsche (1844-1900) berjudul Thus Spoke Zarathustra, terbit tahun $1883,{ }^{7}$ menandai berakhirnya era Modern dan bangkitnya Postmodern. Tetapi Charles Jencks, arsitek Postmodern yang paling berpengaruh mengatakan bahwa, the end of modernism and the beginning of postmodernism took place at:32 P.M. on July 15, 1972. ${ }^{8}$ Jean Francois Lyotard dengan semangat Nietzschean yang menyala-nyala mengemukakan kematian pilar-pilar metanaratif modernisme seperti dialektika roh, emansipasi proletar, hermeneutika dan sains. ${ }^{9}$ Dengan demikian, kehadiran Postmodern merupakan reaksi penolakan terhadap modernisme dan Pencerahan serta asumsi-asumsinya, ${ }^{10}$ sebagaimna ditulis oleh David Harvey sebagai berikut:

The Enlightenment project... took it as axiomatic that there was only one possible answer to any question. From this it followed taht the world could be controlled and rationally ordered if we could only picture and represent it rightly. But this presumed that there existed a single correct mode of representation which, if we could uncover it (and this was what scientific and mathematical endeavors were all about), would provide the means to Enlightenment ends. ${ }^{11}$

${ }^{6}$ For Toynbee, The Postmodern age would be the fourth and final phase of Western history and one dominated by anxiety, irrationalism and helplessness; Arnold J. Toynbee, A Study of History (London: Oxford University Press, 1948), 399-404. Menurut analisis Toynbee, Postmodern dintandai dengan berakhirnya dominasi Barat dan semakin merosotnya individualisme, kapitalisme dan kekristenan; bnd. Grenz, A Primer on..., 31.

${ }^{7}$ Lih. Grenz, A Primer on Postmodern, 133; Zarathustra merupakan model filsuf ciptaan Nietzsche. Yang terpenting dalam munculnya budaya baru (Manusia Super/Ubermensch) adalah bahasa baru (sebuah sistem penafsiran yang komprehensif). Bahasa baru itu menolak segala sistem lain yang berlawanan dengannya; bnd. Allan Megill, Prophets of Extremity: Nietzsche, Heidegger, Foucault, Derida (Berkeley and Los Angeles: University of California Press, 1985), 2.

${ }^{8}$ Ketika pertama kali didirikan proyek rumah Pruitt-Igoe di St. Louis dianggap sebagai lambang arsitektur modern. Tetapi pada sore hari 15 Juli 1972, bangunan itu diledakkan dengan dinamit. Bagi Charles Jencks, peristiwa peledakan ini menandai kematian modernisme dan kelahiran postmodernisme; bnd. Charles Jencks, The Language of Post-Modern Architechture (London: Acadey Editions, 1984), 9.

9 Jean Francois Lyotard, The Postmodern Explained (Minnesota: University of Minnesota Press, 1992), 120.

${ }^{10}$ Bnd. Veith, Postmodern Times..., 42.

${ }^{11}$ David Harvey, The Condition of Posmodernity (Cambridge: Basil Blackwell, 1989), 39. 
Bagi Rene Descartes (1596-1650), dasar segala sesuatu adalah diri manusia yang berpikir (thinking-self), dan diri manusia adalah subjek otonom dan rasional (cogito ergo sum). ${ }^{12}$ Manusia memasuki Postmodern yang ditandai dengan pandangan yang pesimis terhadap kemajuan manusia, disintegrasi kebudayaan dan sikap relativisme terhadap kenyataan dalam dunia. Hasil penelitian George Barna mengindikasikan, $66 \%$ orang Amerika percaya bahwa there is no such thing as absolute truth. ${ }^{13}$ Veith menegaskan, Postmodernism attempts to re-order thought and culture on a completely different basis, accepting reality as a social contruction and avoiding "totalizing discourse" altogether. ${ }^{14}$ Postmodern, pada satu sisi adalah anti metanaratif, antifondasi, sebagaimana dideskripsikan oleh Patricia Waugh: Central to the "Postmodern coundition," of Western history and, in particular, enlightened modernity have broken down. ${ }^{15}$

\section{Hermeneutika}

Kata Hermeneutika (Inggris: hermeneutics) berasal dari bahasa Ibrani Pathar (to interpret), Pithron (penafsiran); Yunani- e`rmhneuw hermēneūo- (explai, expound) yang berarti menginterpretasi, menjelaskan atau menterjemahkan. Kata benda e 'rmhneia secara harfiah dapat diartikan sebagai penafsiran atau interpretasi. ${ }^{16}$ Kata Yunani ini berhubungan dengan dewa Hermes, dewa dalam mitos orang Yunani. ${ }^{17}$ Walter C. Kaiser Jr. mengatakan: The term hermeneutics has become in

\footnotetext{
${ }^{12}$ Grenz, A Primer on..., 10.

${ }^{13}$ George Barna, The Barna Report: What American Believe (Ventura, California: Regal Books, 1991), 83-85.

${ }^{14}$ Veith, Postmodern Times..., 44.

${ }^{15}$ Patricia Wough, Postmodernism: A Reader (London: Edward Arnold, 1992), 5.

16 Harold K. Moulton (ed.), The Analytical Greek Lexicon (Grand Rapids: Zondervan, 1978), 166.

${ }^{17}$ Tugas Hermes adalah mengerti dan menginterpretasi pesan-pesan dari dewa di Gunung Olympus ke dalam bahasa yang dapat dipahami oleh umat manusia Jika terjadi kesalahpahaman, maka akan berakibat fatal bagi seluruh umat manusia. Berhasil-tidaknya misi Hermes tergantung kepada metode atau cara pesan disampaikan; Sebetulnya istilah hermeneutik ini tidak dipakai untuk penafsiran Alkitab saja. Dalam arti dan pemakaian umum, ia menunjukan peraturan-peraturan yang dipergunakan untuk mencari arti sesungguhnya dari, misalnya: kesenian, sejarah, literatur, ilmu purbakala, dan penerjemahan; bnd. Bernard Ramm, Protestan Biblical Interpretation (Grand Rapids: Baker Book House, 1986), 9; William F. Arndt and Gingrich F. Wilbur, A Greek-English Lexicon of The New Testament and Other Early Christian Literature (Chicago: The University of Chicago Press, 1957), 309-310.
} 
creasingly popular in recent decades. ${ }^{18}$ Hermeneutika pada akhirnya diartikan sebagai proses mengubah sesuatu atau situasi ketidaktahuan menjadi mengerti. ${ }^{19} \mathrm{~J}$. Bleicher menggolongkan hermeneutika dalam tiga bagian, yaitu: teori hermeneutika, filsafat hermeneutika dan hermeneutika kritis. Dalam penggolongan ini, Jürgen Habermas ditempatkan sebagai salah satu filsuf hermeneutika terkemuka saat kini, yang menekankan pentingnya hermeneutika yang sadar secara sosiologis; "Hermeneutika Kritis." 20

\section{Fungsi Hermeneutika}

Hermeneutika merupakan upaya memberi makna (meaning) suatu teks. ${ }^{21}$ Namun perlu dicatat, rentang waktu penulisan teks dan pembaca teks sering menciptakan berbagai hambatan. Hermeneutik paling sedikit melibatkan dua aspek, yaitu, eksegese dan eksposisi, walaupun di sisi yang lain, J.I. Packer menawarkan penafsiran biblikal Injili yang dimulai dengan tiga langkah, yaitu, eksegese, sintesa dan aplikasi. ${ }^{22}$

Hermeneutik berfungsi untuk mempelajari prinsip-prinsip penafsiran, baik penafsiran tata bahasa, historis, kebudayaan maupun penerapan praktis dari penafsiran tersebut di mimbar. ${ }^{23}$ Mencari penjelasan tentang apa yang tidak secara jelas di dalam Alkitab, yang didahului dengan langkah observasi atau dapat pula disebut persiapan, ${ }^{24}$ bertanya dan menjawab pertanyaan apa makna teks ini. ${ }^{25}$

${ }^{18}$ Walter C. Kaiser and Moises Silva, An Introduction to Biblical Hermeneutics, (Grand Rapids: Zondervan, 1994), 15. Dalam menjelaskan hermeneutika sebagai prinsip dan seni penafsiran, Silva mengemukakan sejumlah prinsip kerja antara lain: perlunya memahami tata bahasa, latarbelakang sejarah, apa yang dikerjakan oleh teks, setting dari teks, konteks kanonis dari teks itu sendiri, apa kata para penafsir sebelumnya dan apa makna pesan teks bagi kita sekarang ini.

${ }^{19}$ Richard E. Palmer, Hermeneutics (Evanston: Northwestern Univ Press, 1969), 3.

${ }^{20}$ Kees Bertens, Filsafat Barat Abad XX (Jakarta: Gramedia, 1990), 224.

${ }^{21}$ Klass Runia, The Hermeneutics of The Reformers, Calvin Theological Journal 19 (November 1984), 121-122.

22 J.I. Packer, "Infallible Scripture and The Role of Hermeneutics," in Scripture and Truth, peny. D.A. Carson \& John D. Woodbridge (Grand Rapids: Baker, 1992), 345.

23 F.F. Bruce, "Interpretation of The Bible," in Evangelical Dictionary of Theology, editor Walter A. Elwell (Grand Rapids: Baker Books House, 1984), 565.

${ }^{24}$ Richard L. Pratt, He Gave Us Stories: The Bible Student's Guide to Interpreting OT Narratives (Philipsburg, New Jersey: Presbyterian and Reformed, 1990), 3.

${ }^{25}$ Howard G. Hendricks, Living by The Book (Chicago: Moody Press, 1991), 195. 


\section{Urgensitas Hermeneutika}

G.W. Bromiley memberikan empat alasan urgensitas hermeneutik. ${ }^{26}$ Pertama, otoritas Alkitab dihilangkan bilamana arti yang sesungguhnya dilalaikan. Kedua, memahami Alkitab adalah tidak begitu mudah, seperti kelihatannya dan secara umum menyatakannya dalam istilah-istilah yang sederhana, namun hal itu tidaklah menyelesaikan kesulitan-kesulitan yang mengitari semua komunikasi. Ketiga, dalam hal-hal yang dari iman dan tingkah laku, orang-orang Kristen berbeda dengan apa yang Alkitab ajarkan; komitmen kepada otoritas Alkitab bukanlah usaha perlindungan terhadap ketidak-setujuan. Keempat, ada bahaya yang sungguh-sungguh bilamana kita membingungkan otoritas-otoritas, yaitu otoritas dari Alkitab dan otoritas dari penafsiran perorangan akan Alkitab, bilamana pertanyaan hermeneutik tidak diperhatikan.

Interpretasi Alkitab meliputi 3 (tiga) aspek yang perlu diperhatikan, yaitu: antara penulis, teks, dan pembaca. Penulis mengekspresikan pesan kepada pembaca melalui teks yang ditulisnya. Arah komunikasi bersifat satu arah, bergerak dari penulis kepada pembaca. Pembaca tidak dapat berkomunikasi dengan pengarang seperti lazimnya dalam setiap komunikasi, maka respons atau efek diharapkan muncul sebagai akibat proses komunikasi. Banyak kritikus berpendapat bahwa penafsiran yang objektif tidak mungkin dilakukan dan makna yang dimaksud penulis telah hilang selamanya. Dengan demikian setiap komunitas menyediakan tradisi untuk menuntun pembaca dalam memahami suatu teks, dan inilah yang menghasilkan makna. Implikasinya, makna tersebut berbeda-beda di setiap komunitas.

Jadi, pada kenyataannya setiap teks dapat memiliki beragam makna, dan setiap makna itu sah bagi suatu perspektif pembaca atau komunitas tertentu. $^{27}$

\section{Karakteristik Hermeneutika Postmodern}

Secara umum, karakteristik hermeneutika Postmodern, antara lain: Pertama, hal atau peristiwa tidak mempunyai arti yang intrinsik pada dirinya, yang ada hanyalah penafsiran yang terus-menerus terhadap realitas

${ }^{26}$ G. W. Bromiley, “The Interpretation of The Bible," in The Expositor's Bible Commentary, peny. F. E. Gaebelein (Grand Rapids: Zondervan, 1979), 61.

${ }^{27}$ Grant R. Osborne, The Hermeneutical Spiral: A Comprehensive Introduction to Biblical Interpretation (Downers Grove: InterVarsity Press, 1991), 5. 
dan dunia. Kedua, penafsiran-penafsiran tersebut membutuhkan penelitian sesuai dengan konteksnya, sedangkan kita adalah bagian dari konteks itu sendiri. Ketiga, penafsiran tidak tergantung kepada faktor objektif dari teks atau pengarangnya, tetapi kepada pandangan relatif dari penafsir. Keempat, bahasa tidaklah netral melainkan relatif dan dipakai untuk menyampaikan suatu ideologi atau nilai-nilai tertentu. ${ }^{28}$

\section{Problema Hermeneutika Postmodern}

Dalam Studi Hermeneutika saat kini, tak bisa dilepaskan dari pengaruh Posmodern. Pendekatan hermeneutika dibawa kepada pendekatan-pendekatan ilmu sastra yang dikenal dengan nama-nama: Reader-response, deconstruction, feminist criticism, ideological criticism, autobiographical criticism, dan lain sebagainya. Dengan munculnya reader-response criticism maka terjadilah pergeseran paradigma aktivitas membaca teks. Tiap orang dapat membaca Alkitab dan berhak menafsirkan artinya sebagaimana ia atau golongannya mengartikannya.

Namun percu dicatat, bahwa penafsiran tanpa hermenutika yang benar menimbulkan problema serius. Munculnya publikasi biblika seperti interpretasi feminis merupakan petunjuk semakin meluasnya pendekatanpendekatan Postmodern dalam dunia hermeneutika.

Hakikatnya, suatu teks merupakan dasar pemaknaan teks. Tidak salah jika dikatakan bahwa hermeneutika bergantung pada konsep tentang teks. ${ }^{29}$ Dengan melalaikan maksud asli teks Alkitab akan menimbulkan krisis yang dalam banyak cara menimbulkan krisis-krisis teologi yang lain. George M. Landes mengatakan bahwa krisis yang paling dasar dalam studistudi biblikal haruslah ditempatkan dalam disiplin hermeneutika. ${ }^{30}$

Friedrich Schleiermacher (1768-1834), pemikir utama jalur hermeneutika yang berorientasi pada penulis terkenal sebagai: to reproduce the whole internal process of an author's way of combining thoughts...

\footnotetext{
${ }^{28}$ Henry Efferin, Jurnal Pelita Zaman, No.14.

${ }^{29}$ Upaya memahami teks dari perspektif pengarang menegaskan bahwa teks hanya dapat dipahami bila dapat mengungkapkan maksud pengarang menulis teks tersebut. Langkah pertama memberi makna suatu teks diawali dengan memahami penulis dan konteks penulis berada. Jadi, proses pembacaan difokuskan pada usaha merekonstruksi konteks suatu teks dan harapan maksud sebenarnya penulis dapat terungkap.

${ }^{30}$ George M. Landes, "Towards an Exegetical Theology: Biblical Exegesis in Crisis, What is the Exegetical Task in a Theological Context?" 274; seperti dikutip oleh Walter C. Kaiser, Jr. (ed.), Toward and Exegetical Theology: Biblical Exegesis for Preaching and Teaching (Grand Rapids, Michigan: Baker Book House, 1981), 17.
} 
Explanation of words and contents are not themselves interpretation but only elements of it. $^{31}$ William Dilthey (1833-1911) dan E.D. Hirsch ${ }^{32}$ serta pakar lainnya kemudian berjalan di atas landasan yang telah dibangun Schleiermacher. Hans-Georg Gadamer membuka jalan terhadap pendekatan yang menekankan partisipasi pembaca dalam memberi makna suatu teks. Jürgen Habermas sendiri menghargai dan menyetujui sikap Gadamer.

\section{LANDASAN PEMIKIRAN JÜRGEN HUBERMAS}

Untuk memahami pemikiran-pemikiran atau gagasan-gagasan Jürgen Hubermas yang memiliki relasi dengan hermeneutika, maka terlebih dahulu perlu menganalisis riwayat hidup, latarbelakang pemikirannya, dan kerangka hermeneutiknya.

\section{Riwayat Hidup}

K. Bertens meringkaskan riwayat hidup Jürgen Habermas dalam buku Filsafat Barat Abad XX, sebagai berikut:

Jürgen Habermas dilahirkan di Gummersbach tahun 1929. Di Universitas kota Gottingen, ia belajar kesusastraan Jerman, sejarah dan filsafat (a.l. pada N. Hartmann) dan juga mengikuti kuliah di bidang psikologi dan ekonomi. Sesudah beberapa waktu di Zurich, ia meneruskan studi filsafat di Universitas Bonn. Tahun 1954 ia meraih gelar 'doktor filsafat,' berdasarkan sebuah disertasi tentang Das Absolute und die Geschichte, suatu karya yang masih secara mendalam dipengaruhi oleh filsafat Heidegger. ${ }^{33}$

Habermas sangat populer di kalangan mahasiswa Jerman dan oleh beberapa golongan dianggap sebagai ideolog mereka. Ia adalah salah seorang filsuf Jerman paling terkemuka dalam era 1970-an. Pada tahun tersebut ia menerbitkan buku Protesbewegung und Hochschulreform, suatu buku yang menjadi best-seller di Jerman. Salah satu kritik yang menarik atas Kebenaran dan Metode berasal dari Jürgen Habermas.

${ }^{31}$ Stanley J. Grenz, Revisioning Evangelical Theology (Downers Grove: Inter Varsity, 1993), 67.

${ }^{32}$ Bnd. E.D. Hirsch, Validity in Interpretation (New Haven: Yale Univ. Press, 1967); and idem, The Aims of Interpretation (Chicago: University of Chicago Press, 1976).

${ }^{33}$ Bertens, Filsafat Barat Abad..., 213. 


\section{Latarbelakang Pemikiran Habermas}

Jürgen Habermas (1929- ）, tidak diragukan lagi menjadi salah satu filsuf terbesar abad ini. Sebagai pemikir generasi baru (generasi kedua) Mazhab Frankfurt (Frankfurt School), ${ }^{34}$ Habermas berusaha meneruskan pemikiran para pendahulunya (M. Horkheimer, Th. Adorno, H. Marcuse), sekaligus mengusulkan proyek-proyek baru yang lebih otentik. Meskipun gagasan-gagasan Habermas tidak berpusat pada hermeneutika, namun ideidenya tersebut memberi warna pada pustaka hermeneutika.

Tidaklah mudah memahami secara tepat dan sistematis seluruh pemikiran atau gagasan Habermas, yang luas dan mendalam; lagi pula pemikirannya amat dinamis dan terus berkembang hingga kini. Untuk memahami gagasan-gagasannya, maka harus terlebih dahulu menempatkan seluruh pemikirannya dalam konteks Teori Kritis yang ditawarkan Mazhab Frankfurt, bahkan lebih jauh lagi dalam tradisi pemikiran Hegelianisme, Marxisme dan psikoanalisis Sigmund Freud. Ketiga pemikiran kritis tersebut memahami kata kritik secara berbeda.

Hegel memahami kritik sebagai refleksi atau refleksi diri atas rintangan-rintangan, tekanan-tekanan dan kontradiksi-kontradiksi yang menghambat proses pembentukkan-diri dari rasio dalam sejarah. Karl Marx sebagai seorang Hegelian, memahami kritik sebagai usaha-usaha emansipatoris dari penindasan dan alienasi yang dihasilkan oleh hubungan-hubungan kekuasaan dalam masyarakat. Sigmund Freud memahami kritik sebagai pembebasan individu dari irasionalitas menjadi rasionalitas, dari ketidaksadaran menjadi kesadaran. ${ }^{35}$

Habermas juga amat dipengaruhi oleh pragmatisme Dewey, filsafat analisis-nya Wittgenstein dan J.L. Austin, serta banyak pemikir lainnya. Oleh karena itu, dapatkah dimunculkan dimensi-dimensi hermeneutik-

${ }^{34}$ Sekolah Frankfurt mengembangkan suatu teori yang dinamakan Teori Kritis. Teori Kritis bukan sekedar kontemplasi pasif prinsip-prinsip objektif realitas melainkan bersifat emansipatoris; yang harus memenuhi 3 syarat: Pertama, Bersikap kritis dan curiga terhadap zamannya, seperti yang telah dilakukan Karl Marx terhadap sistem kapitalisme. Kedua, Berpikir secara historis, berpijak pada masyarakat dalam prosesnya yang historis. Ketiga, tidak memisahkan teori dan praktis, tidak melepaskan fakta dari nilai semata-mata untuk mendapat hasil yang objektif; Bnd. Frans Magnis Suseno, Para Filsuf Penentu Gerak Zaman (Yogyakarta: Kanisius, 1992), 141-154. 2001), 60-61

${ }^{35}$ Donny Gahral Adian, Arus Pemikiran Kontemporer (Yogyakarta: Jalasutra, 
teologis dari Teori Kritis Habermas ini? ${ }^{36}$ Selain itu, tidak mungkin memahami pemikiran Habermas tanpa menyadari konteks kehidupan bangsa Jerman pada masa mudanya. Habermas dibingungkan pertanyaan, mengapa bangsa Jerman, yang melahirkan gagasan-gagasan kemanusiaan yang unggul, mulai dari Kant sampai Marx dengan tema-tema emansipasi, kebebasan, sekaligus menyediakan lahan subur bagi Hitler dan Nazisme? ${ }^{37}$

\section{Kerangka Hermeneutika Habermas}

Meskipun gagasan-gagasan Jürgen Habermas tidak berpusat pada hermeneutik, dan karya-karyanya-pun tidak secara khusus membicarakan hermeneutik sebagai ide tunggalnya, namun pemikiran-pemikirannya itu mendukung pustaka hermeneutik. Gagasan hermeneutikanya dapat ditemui di dalam tulisannya berjudul Knowledge and Human Interest. ${ }^{38}$ Habermas mengikuti tiga bentuk penyimpulan, yaitu: deduksi, induksi dan abduksi atau proses abdutif. ${ }^{39}$

Dalam penyelidikan ilmu-ilmu hermeneutik, ia tertarik untuk menyingkapkan kerangka metodologis dan kepentingan yang menentukan dalam ilmu hermeneutik. Bagi Habermas, klaim-klaim pengetahuan dalam ilmu-ilmu hermeneutik grasp interpretations of reality with regard to possible intersubjectivity of action-orieting mutual understanding specific to a given hermeneutic sating point. ${ }^{40}$ Ia memusatkan kritik dan studinya pada pemikiran hermeneutik Dilthey, bahwa pemahaman hermeneutik harus mengintegrasikan ketiga kelas kehidupan, yakni: bahasa, tindakan dan pengalaman. Habermas sendiri menyetujui sikap Gadamer yang menentang pendirian objektivisme. Ia juga menghargai usaha Gadamer merefleksikan kesadaran diri hermeneutis, sekaligus setuju pada pendapat

${ }^{36}$ Gary M. Simpson, "Theologia Crucis and The Forensically Fraught World: Engaging Helmut Peukert and Jürgen Habermas" in Journal of the American Academy of Religion. Vol. LVII, No. 3, Th.1989, 509.

${ }^{37}$ Richard J. Berstein (ed.), “Introduction," dalam Habermas and Modernity, (Cambridge: Polity Press \& Oxford, Basil Blackwell, 1986), 2.

${ }^{38}$ Habermas, Knowledge and Human..., 144.

${ }^{39}$ Dengan deduksi, Habermas ingin membuktikkan bahwa sesuatu 'seharusnya' berperilaku dalam cara tertentu; dengan induksi ia ingin membuktikkan bahwa sesuatu pada kenyataannya berperilaku dalam suatu cara tertentu; dan dengan abduksi ia ingin membuktikkan bahwa sesuatu mungkin akan berperilaku menurut suatu cara tertentu.

${ }^{40}$ Habermas, Ibid, 195. 
Gadamer mengenai ketergantungan subjek yang berbicara dengan bahasanya. $^{41}$

Menurut Habermas, hermeneut atau penafsir tak dapat memahami sepenuhnya makna suatu fakta, sebab ada juga fakta yang tidak dapat diinterpretasi. Hermeneutika membutuhkan pemahaman tentang makna yang mampu mengartikan hubungan-hubungan simbol sebagai hubungan fakta. Habermas harus melawan klaim Gadamer bahwa hermeneutik memiliki arah atau penekanan yang universal karena hermeneutika berpusat pada bahasa. ${ }^{42}$ Yang ditakutkan oleh Habermas adalah terjadinya pseudocommunication yang memungkinkan terjadinya "komunikasi yang terdistorsi secara sistematis." Ia berpendapat bahwa bahasa itu sendiri didominasi oleh kekuatan-kekuatan sosial dan satu-satunya jawaban adalah kritik ideologi pada inti hermeneutika. Ketimbang mengandaikan sebuah hermeneutika yang universal, Habermas menawarkan dipakainya Depth Hermeneutics yang diyakininya tidak akan mengalami distorsi yang muncul dari luar. Habermas menulis sebagai berikut:

Even the implisit knowledge of the pre-conditions of systematically distored communication which is really prespposed in the usage of communicative competense characterictioc depthe hermeneuticseven this is sufficient to put in question the ontological selfunderstanding of hermeneutics which Gadamer, following on Heidegger, makes explicit. ${ }^{43}$

\section{KONTRIBUSI GAGASAN HABERMAS BAGI HERMENEUTIKA POSTMODERN}

Skeptisisme Postmodern menghasilkan dunia yang selalu dipenuhi pluralitas yang saling bertentangan dan tak pernah selesai. Komitmen kepada Allah dalam Kristus, mengharuskan kita berdiri teguh melawan skeptisisme radikal postmodern, yakni lenyapnya metanaratif - "titik pusat." Namun harus selalu siuman dan patut dicatat bahwa suatu faham baru selalu ada sisi postif dan negatifnya.

41 Anthony C. Thiselton, New Horizons in Hermeneutics (Grand Rapids: Zondervan, 1992), 12.

${ }^{42}$ Bnd. Werner G. Jeanrond, Teks and Interpretation as Categories of Theological Thingking (Dublin: Gill and Macmillan, 1988), 22-23.

${ }^{43}$ Jeanrond, Teks and Interpretation as Categories of Theological Thingking, 23; Habermas amat terganggu dengan upaya Gadamer merehabilitasi konsep prasangka (prejudice) dalam konteks hermeneutisnya. 
Berkaitan dengan hal di atas, telah bermunculan pemikir-pemikir dari kaum injili yang menggunakan tiga metode pendekatan terhadap semangat postmodern, yakni: akomodasi, sintesis juga kontra-postmodern. Fakta menunjukan bahwa kritik postmodern dalam beberapa bagian lebih sesuai dengan pemahaman iman Kristen. Selama kita mengakui validitas keyakinan-keyakinan kristiani secara absolut, metanaratif, keyakinankeyakinan tersebut pasti mengendalikan penafsiran. Hanya dengan mengidentifikasikan mereka apa adanya, suatu perkiraan terhadap kebenaran secara teologis dan budaya, barulah kita dapat tetap menempatkan mereka di dalam perspektif postmodern yang benar. ${ }^{44}$

Postmodern menolak anggapan pencerahan bahwa pengetahuan itu pasti dan kriteria kepastian itu terletak pada rasio manusia. Iman Kristen juga menolak kalau metode ilmiah dan rasional itu dianggap sebagai satusatunya kriteria kebenaran. Sebagaimana dikatakan oleh Blaise Pascal, "Hati manusia mempunyai logikanya sendiri yang tidak dapat dipahami oleh rasio manusia" (bnd. Ams 3:7; Ul 29:29; Flp 4:7; 1Kor 13:12). Berkaitan dengan hal inilah penulis mengamati adanya dimensi-dimensi gagasan hermeneutik posmodern Jürgen Habermas yang dapat didistribusikan ke dalam hermeneutis-teologis.

\section{$\underline{\text { Kritik Atas Positivisme }}$}

Pada tahun 1960-an di Eropa, muncul sebuah perbantahan hebat mengenai positivisme, yang dikenal dengan nama Possitivismusstreit. Diskusi ini menempatkan metode ilmu sosial sebagai bahan pembicaraan. Semula Theodor W. Adorno berdebat dengan Karl Popper, yang masingmasing mewakili pendirian kritis-dialektis dan pendirian positivistis. Setelah itu tampil Hans Alber dan Jürgen Habermas. Perdebatan ini mempertajam permasalahan dan pemikiran masing-masing pihak. ${ }^{45}$

Sejak awal Habermas menempatkan pendiriannya dalam alur pemikiran Mazhab Frankfurt, yang berjuang menentang positivisme dan objektivisme. Habermas mengikuti pemikiran para pendahulunya, menegaskan penolakannya terhadap positivisme, yang berusaha memisahkan ilmu dan kepentingan (interest), agar ilmu bisa hadir secara netral tanpa pemihakan (disinterested). Akibatnya ilmu (theoria)

44 William Larkin, Culture and Biblical Hermeneutics (Grand Rapids: Baker Book House, 1988), 75-95.

${ }^{45}$ Karangan-karangan penting mengenai perdebatan ini dikumpulkan oleh Th. Adorno dalam buku The Positivist Dispute in German (New York: 1976). 
dipisahkan secara radikal dengan praksis dan menjadi a-historis secara $a$ sosial.

Menurut Habermas, kepentingan atau minat adalah orientasi dasar yang berakar dalam kondisi fundamental khusus dari reproduksi yang mungkin dan kelangsungan hidup spesies manusia, yaitu kerja atau karya dan interaksi. Sebagai contoh misalnya: sesuatu yang diminati atas dasar penalaran adalah masuk akal. Jadi, dari hal yang menyenangkan bisa muncul kecenderungan untuk sesuatu yang baik dan masuk akal. ${ }^{46}$ Tetapi, mengapa kepentingan atau minat dimasukkan ke dalam hermeneutik? Bagi Habermas, pengetahuan dan minat itu pada dasarnya adalah satu dan keduanya berpadu atau berbaur menjadi satu dalam bahasa yang dipakai.

Akibat semua tindak-tanduk positivisme ini, Habermas melontarkan tuduhan bahwa ilmu-yang bebas-nilai pada akhirnya hanya ingin mempertahankan status-quo masyarakat. Baginya, usaha memperoleh pengetahuan yang objektif, yang terbebas dari kepentingan-kepentingan, sebenarnya usaha tersebut didorong oleh sebuah kepentingan yang lebih dalam, yaitu agar dicapai sebuah teori murni. ${ }^{47}$

Dalam interpretasi, bahasa mendapatkan tempat yang utama. Untuk mencapai pemahaman dengan perantaraan bahasa diperlukan pengarahan, yaitu semacam mekanisme tindakan yang terkoordinasikan. Sehingga, walaupun mempergunakan konsensus tertentu, tetap dapat mengkoordinir diri sendiri ke arah tujuan tertentu.

\section{$\underline{\text { Teori Kritis }}$}

Habermas mengajukan sebuah pemecahan epistemologis melalui apa yang kemudian disebut Teori Kritis. Bagi Habermas, proses memperoleh pengetahuan selalu dilandasi kepentingan tertentu. Teori Kritis senantiasa bersifat historis, berpijak pada realitas konkret, serta menjadi kritik imanen atas tatanan yang melanggengkan status-quo. Namun yang

\footnotetext{
${ }^{47}$ Di sini Habermas menyetujui upaya Edmund Husserl yang juga mencela gejala objektivisme yang memisahkan teori dari kenyataan sesehari (Lebenswelt). Namun bagi Habermas, kesalahan Husserl adalah menolak objektivisme itu sembari memunculkan bentuk objektivisme lainnya, ketika ia berusaha memperoleh sebuah teori yang murni. Lih. Knowledge and Human Interest, 302-306. Habermas menulis, "While criticizing the objectivist self-understanding of the sciences, Husserl succumbs to another objectivism, which was always attched to the traditional concept of theory," 306.
} 1999), 88

${ }^{46}$ E. Sumaryono, Hermeneutik: Sebuah Metode Filsafat (Yogyakarta: Kanisius, 
menjadi sasaran kritis teori ini bukan hanya realitas sosial, tetapi juga pendekatan-pendekatan ilmiah atas realitas sosial itu sendiri.

Bagi Habermas, Teori Kritis mengambil sikap kritis baik terhadap ilmu-ilmu sosial dewasa ini maupun kenyataan sosial yang dilukiskannya. Ia kritis terhadap pendekatan-pendekatan ilmiah yang tidak mampu menjelaskan paradoks-paradoks rasionalisasi kemasyarakatan karena pendekatan-pendekatan itu membuat sistem-sistem sosial yang kompleks sebagai objek mereka hanya dari salah satu sudut pandang abstrak, tanpa memperhitungkan asal-usul historis (dalam arti sosiologi reflektif). ${ }^{48}$

Ilmu tidak pernah bebas-nilai, termasuk pula teologi. Selain itu Habermas juga mencela kecenderungan positivisme yang berusaha melepaskan teori dari praksis, demi memperoleh sebuah teori murni. Tak jarang pula teologi Kristen terjebak dalam kecenderungan semacam ini.

Dengan demikian jelaslah bahwa Teori Kritis berurusan dengan usaha memperoleh pengetahuan (epistemologi) dengan cara-cara yang kritis, serta peka terhadap kepentingan manusiawi di balik setiap upaya ilmiah. Dalam hal ini, Habermas sendiri membedakan pengetahuan dalam tiga cakupan: ilmu yang memanfaatkan keterangan teknis yang diperoleh secara langsung atau secara analitis; sejarah, yang menafsirkan bahasa sesuai dengan Gadamer; dan ilmu-ilmu sosial yang menggunakan perenungan untuk membebaskan atau meng-“emansipasi” orang-orang dari dominasi kekuatan dan-kekuatan-kekuatan sejarah. ${ }^{49}$

\section{$\underline{\text { Rasio dan Praksis }}$}

Habermas juga mempersoalkan makna Rasio dalam seluruh percakapan yang sedang diikutinya. Bagi para pemikir Mazhab Frankfurt rasio telah menjadi alat yang netral untuk mengoperasionalisasikan sebuah sistem. Rasio semacam ini oleh Horkheimer disebut rasionalitas-bertujuan. Yang dimaksud di sini, rasio sekedar menjadi alat (instrument) belaka di luar dirinya sendiri, yaitu kepentingan-kepentingan ideologis. Akhirnya,

\footnotetext{
${ }^{48}$ Habermas membagi tindakan menjadi 4 jenis: tindakan teologis (konsep pokok tindakan ini adalah keputusan); tindakan normatif (konsep pokok dalam tindakan ini adalah pemenuhan terhadap norma); tindakan dramaturgik (konsep pokok adalah penampilan diri di hadapan umum atau masyarakat); tindakan komunikatif (konsep pokok dalam tindakan ini adalah "interpretasi"); bnd. J. Habermas, The Theory of Communicative Action, Vol. II (Boston: Beacon Press, 1984), 375.

${ }^{49}$ Bnd. Habermas, Knowledge and Human..., 308-311.
} 
menurut Marcuse, "masyarakat modern adalah rasional secara parsial tetapi irasional dalam keseluruhan." Rasionalitas yang irasional! ${ }^{50}$

Mazhab Frankfurt berhasil menunjukan bahwa kesalahan ini terjadi karena rasio dipisahkan dari praksis, yaitu tindakan manusia untuk merealisasikan hidup yang baik. Rasio dimurnikan dari unsur penilaian dan moralitas. Secara epistemologis akhirnya mereka sendiri pun pesimis terhadap Teori Kritis, dengan kekuatiran bahwa rasionalitas yang kritis pun bisa membeku dan menjadi ideologis. Di sinilah persimpangan muncul; Habermas menjalani arah lain yang jauh lebih optimis terhadap rasionalitas.

Permasalahan rasio ini oleh Habermas diletakan dalam konteks yang lebih luas, yaitu nisbah antara teori dan praksis. Bagi Habermas, pengetahuan bukanlah persoalan kontemplasi, melainkan mendorong praksis perubahan sosial. Praksis di sini adalah tindakan dasar manusia yang didorong oleh kesadaran rasional. Dari Karl Marx, Habermas mewarisi konsep tentang kerja sebagai syarat keberadaan manusia dan tidak terikat pada bentuk-bentuk masyarakat. Kerja adalah proses yang terdapat antara manusia dengan alam, dimana manusia melalui tindakannya menengahi, mengatur dan mengawasi pertukaran barang-barang yang mereka miliki dengan alam. Jadi, kerja mempunyai fungsi sintesis, namun juga dapat dijauhkan dan diasingkan dari manusia. ${ }^{51}$ Dalam studinya atas pemikiran Hegel, Habermas menemukan bahwa praksis pada dasarnya tidak hanya berarti kerja (arbeit), namun juga komunikasi (communication). Namun Habermas juga mengritik Marx dengan mengatakan bahwa Marx telah menipu dirinya sendiri dalam hal yang berkaitan dengan hakikat refleksi yang ia kembalikan ke kerja karena Marx kemudian menarik proses refleksi ke tingkat tindakan instrumental. ${ }^{52}$

Harus mulai diusahakan sebuah rancang bangun model Gereja sebagai sebuah komunitas aksi komunikatif, ${ }^{53}$ dimana diskursus imankomunikasi iman-menjadi praksis bersama. Konsep pokok dalam praksis adalah interpretasi. Dalam interpretasi, bahasa mendapatkan tempat yang utama. Untuk mencapai pemahaman dengan perantaraan bahasa diperlukan semacam mekanisme praksis yang terkoordinasikan. Sehingga, walaupun mempergunakan konsensus tertentu, kita dapat mengkoordinir diri kita sendiri ke arah tujuan tertentu.

${ }^{50} \mathrm{H}$. Marcuse, One Dimensional Man: Studies in the Ideologyof Advanced Industrial Society (London: Routledge \& Kegan Paul, 1964), 134.

${ }^{51}$ Sumaryono, Hermeneutik: Sebuah Metode..., 89-90.

${ }^{52}$ Bnd. Bertens, Filsafat Barat Abad..., 177-178.

${ }^{53}$ Paul Lakeland, Theology and Critical Theory: The Discouse of the Church, (Nashville: Abingdon Press, 1990), 103-137. 
Habermas memperlihatkan bahwa praksis berdasarkan rasio instrumental bisa menjadi praksis dari manusia, namun tidak boleh menjadi praksis terhadap sesama. Kehebatan Habermas adalah mengajukan secara konsisten perlunya pemakaian praksis melalui paradigma komunikasi daripada sekedar memakai paradigma kerja. ${ }^{54}$

\section{$\underline{\text { Refleksi Diri }}$}

Dalam Knowledge and Human Interest Habermas melontarkan tesis keempatnya yang berbunyi, "in the power self-reflection, knowledge and interest are one." 55 Di sini Habermas berdiri dalam tradisi pemikir Jerman Fichte bahwa rasio mengandung dua segi, yaitu: kehendak dan kesadaran.

Bagi Hegel, rasio dipandang memiliki kemampuan untuk menemukan hambatan yang merintangi perkembangan diri untuk mencari otonomi kedewasaan. Oleh Habermas, kedewasaan diartikan sebagai konsensus-bebas-hambatan, yang dicapai melalui refleksi-diri, kita terbebas dari dogmatisme, "Self-reflection is at once intuition and emancipations, comprehension and liberation from dogmatic dependence." ${ }^{, 56}$ Dalam banyak hal, para interpreter tidak dapat bebas dari titik mula hermeneutika, yaitu refleksi diri. Habermas mempertahankan pendapatnya bahwa minat yang tertinggi dan dasar dari semua minat yang lain adalah minat terhadap diri sendiri. Lalu, apakah minat terhadap diri sendiri akan menjadi faktor penentu dalam pemahaman epistemologi seperti hermeneutika? Habermas mengatakan bahwa penalaran mempunyai minat praktis yang menjadi milik penalaran itu sendiri. Ini berarti bahwa bila kita berefleksi, maka refleksi itu sekaligus merupakan intuisi dan emansipasi, pemahaman dan kebebasan dari ketergantungan kepada dogma. Dengan memahami diri sendiri maka kita juga memahami dunia.

Interpreter tidak dapat mengawali interpretasinya tanpa terlebih dahulu melibatkan dirinya dalam refleksi diri. Inilah alasan Habermas mengatakan bahwa "membuka rahasia interpretasi terhadap diri sendiri adalah tugas hermeneutika." ${ }^{57}$ Sebab itu, diri sendiri menjadi titik tolak interpretasi, dan ini menyebabkan hermeneutika menjadi penting.

\footnotetext{
${ }^{54}$ J. Habermas, Towards a Rational Society (London: Heinemann, 1971), 93.

${ }^{55}$ Habermas, Knowledge and Human..., 314.

${ }^{56}$ Ibid., 208.

${ }^{57}$ Habermas, The Theory of Communicative..., 169.
} 
Habermas memperkaya konsep refleksi-diri ini dengan teori psikoanalisis-nya Freud. ${ }^{58}$ Bagi Paul Ricoeur, ide-ide Freud melengkapi para hermeneut dengan landasan yang kokoh untuk interpretasi. ${ }^{59}$ Bahkan, mimpi juga memerlukan hermeneutik batin dan refleksi diri.

Praktek penafsiran mimpi merupakan sebuah bentuk hermeneutika yang amat mendalam. Karena, berbeda dengan hermeneutika biasa yang memakai bahasa sesehari sebagai teks, panafsiran mimpi mempergunakan bahasa yang kacau sebagai teks yang perlu dianalisis. ${ }^{60}$ Dalam hal ini hermeneutika mempunyai tugas ganda, yaitu menempatkan dirinya sendiri sebagai orang yang bermimpi untuk kemudian menyibukkan diri dalam penjelasan kausal dan ilmiah, serta interpretasi. Ia menjadi semacam analisis yang harus menyusup masuk ke bawah isi yang mewujud dari teks mimpi, yang menyembunyikan kejanggalannya dan analisis harus bisa menguraikan kejanggalan tersebut. ${ }^{61}$

Tidak ada satu batas pun dalam mimpi. Berdeda pula dengan hermeneutika biasa yang menghadapi teks transparan, psikoanalisis berhadapan dengan teks yang terselubung. Karena itu, Habermas menyebut psikoanalisis sebagai Hermeneutika Dalam/Batin (Tiefenhermeneutik atau Dept Hermeneutics). Terhadap bentuk atau objek semacam itu interpreter diharapkan menghubungkan dan menjalin pola-pola tindakan dalam upayanya untuk menguraikan misteri dan mencari penjelasannya melalui makna yang tersembunyi di balik bahasa atau mimpi.

\section{PENUTUP: EVALUASI DAN REFLEKSI}

Pertama, konteks sosial postmodern terdiri dari banyak bagian dan berubah-ubah, yang memengaruhi hermeneutika seseorang. Hermeneut menjadi titik tolak hermeneutika, dan ini menyebabkan hermeneutika menjadi penting. Karenanya, bila hermeneut meninggalkan makna teks dan maksud penulis, maka ia akan tenggelam dalam lautan relativitas postmodern, dan tak ada dimensi metanaratif yang absolut.

Kedua, pewahyuan ilahi itu sendiri terkondisi secara budaya karena dikomunikasikan kepada berbagai budaya dalam berbagai bahasa yang tidaklah netral dan tak dapat dihapuskan oleh postmodern.

${ }^{58}$ Habermas, The Theory of Communicative..., 209.

${ }^{59}$ Paul Ricoeur, Freud and Philosophy (New Haven \& London: Yale Univ. Press, 1970), 217.

${ }^{60}$ Habermas, Knowledge and Human..., 190-203.

${ }^{61}$ Sumaryono, Hermeneutik: Sebuah Metode..., 93. 
Ketiga, teologi kritis bisa memberi kemungkinan mengerjakan refleksi-diri terus-menerus. Kritis atas kenyataan dunia harus dibarengi dengan kritik terhadap diri sendiri. Untuk itu diperlukan sebuah pola hermeneutik yang kritis atas teks-teks mapan yang ada.

Keempat, jika hendak menginterpretasi secara benar dan tepat, maka kita harus mengupayakan dialog antara bahasa dan pengalaman di satu sisi dengan tindakan di sisi lain. Tidak memisahkan teori dan praksis, tidak melepaskan fakta dari nilai semata-mata untuk mendapat hasil yang objektif.

Kelima, bahasa mencakup seluruh makna dan oleh sebab itu hermeneutika memiliki implikasi yang universal. Pentingnya sosiologi pengetahuan sebagai suatu sarana penafsiran.

Keenam, kekuatan-kekuatan ideologis mengendalikan hermeneutika hampir semua orang. Calvinis atau Armenian, Reformed atau Dispensasional, Teolog Proses atau Pembebasan, tiap komunitas orang percaya telah memberikan kecenderungan-kecenderungan ideologis tertentu yang menuntun penafsiran. Karenanya, hermeneutika harus membebaskan pemahaman dari ideologi.

Ketujuh, pemahaman hermeneutik sifatnya global, yaitu mengandaikan adanya tujuan khusus. Setiap komunikasi yang sehat adalah komunikasi dimana setiap partisipan bebas untuk menentang klaim-klaim tanpa ketakutan akan koersi, intimidasi, deceit dan sebagainya. Melalui tindakan komunikatif, pemahaman hermeneutik mempunyai bentuk yang hidup, yaitu kehidupan sosial Postmodern. 